\title{
ANALISIS KEMAMPUAN MENGEMBANGKAN BAHAN AJAR YANG KONTEKSTUAL BERBASIS POWER POINT PADA GURU SMP NEGERI 11 MERAUKE
}

\section{ANALYSIS OF ABILITY TO DEVELOP CONTEXTUAL TEACHING MATERIALS BASED ON POWER POINT ON TEACHERS OF SMP NEGERI 11 MERAUKE}

\author{
${ }^{1)}$ Syamsul Bahri, ${ }^{2)}$ Helga C. A. Silubun, ${ }^{3)}$ Minuk Riyana \\ ${ }^{1,2)}$ Prodi Pendidikan Fisika, Universitas Musamus, Jl. Kamizaun Mopah Lama, Merauke \\ ${ }^{3)}$ Prodi Pendidikan Matematika, Universitas Musamus, Jl. Kamizaun Mopah Lama, Merauke \\ *Korespondensi Penulis. Email: syamsul_fkip@unmus.ac.id
}

\begin{abstract}
ABSTRAK
SMP Negeri 11 Merauke terletak di Distrik Sota yang peserta didiknya cukup beragam, bahkan ada dari negara tetangga, yaitu PNG. Hasil ujian nasional peserta didik, khususnya mata pelajaran IPA pada tiga tahun terakhir terus mengalami penurunan. Hal ini menunjukkan bahwa hasil belajar peserta didik tergolong rendah. Salah satu hal yang menyebabkan rendahnya hasil belajar peserta didik adalah pembelajaran yang belum dilengkapi dengan media pembelajaran yang kontekstual.Tujuan kegiatan ini adalah untuk meningkatkan kemampuan guru IPA agar mampu mebuat media pembelajaran yang kontekstual dengan menggunakan PowerPoint. Media pembelajaran ini diharapkan dapat meningkatkan hasil belajar peserta didik, khususnya pada ujian nasional. Adapun subjek dalam kegiatan ini adalah guru-guru SMP Negeri 11 Merauke yang terletak di Distrik Sota yang merupakan daerah perbatasan antara RI dengan Papua New Guinea yang berjumlah 15 orang. Metode pelaksanaan kegiatan pengabdian adalah dengan melakukan pelatihan, pendampingan serta pembuatan media pembelajaran IPA yang kontekstual dengan mengintegrasikan ke dalam PowerPoint. Hasil pelaksanaan kegiatan menunjukkan bahwa terjadi peningkatan kemampuan menggunakan PowerPoint untuk media pembelajaran sebesar 24,5\%, yaitu dari 27,3\% menjadi 45,7\%. Secara umum, pengetahuan dan kemampuan guru menggunakan PowerPoint sebagai media pembelajaran masih tergolong rendah cukup rendah. Oleh karena itu, diharapkan kepada seluruh stakeholder untuk memperhatikan kemampuan guru di dalam menggunakan TIK, khususnya yang berhubungan langsung dengan pembelajaran. Hal ini tentunya akan mendukung karakteristik pembelajaran abad 21 serta pembelajaran di era revolusi industri 4.0 (I4.0).
\end{abstract}

Kata kunci: media pembelajaran; pembelajaran kontekstual; power point

\section{ABSTRACT}

SMP Negeri 11 Merauke is located in the Sota District where students are quite diverse, even from neighboring countries, namely PNG. The results of national examinations of students, especially science subjects in the last three years have continued to decline. This shows that the learning outcomes of students are classified as low. One of the things that cause the low learning outcomes of students is learning that is not yet equipped with contextual learning media. The purpose of this activity is to improve the ability of science teachers to be able to create contextual learning media using PowerPoint. This learning media is expected to improve student learning outcomes, especially on national examinations. The subjects in this activity were the teachers of Merauke Public Middle School 11 located in the Sota District which is the border area between the Republic of Indonesia and Papua New Guinea, amounting to 11 people. The method of implementing community service activities is by conducting training, mentoring and making contextual science learning media by integrating into PowerPoint. The results of the implementation of the activity showed that there was an increase in the ability to use PowerPoint for learning media by $24.5 \%$, from $27.3 \%$ to $45.7 \%$. In general, the knowledge and ability of teachers to use PowerPoint as a learning medium is still quite low. Therefore, it is expected that all stakeholders pay attention to the ability of teachers to use ICT, especially those directly related to learning. This certainly will support the characteristics of 21 st century learning and learning in the industrial revolution 4.0 (I4.0).

Keywords: learning media; contextual learning; power point 


\section{PENDAHULUAN}

SMP Negeri 11 Merauke merupakan salah satu sekolah yang terletak di Sota, Kecamatan Sota, Kabupaten Merauke. Sekolah ini berjarak sekitar $79 \mathrm{~km}$ dari kota Merauke. SMP Negeri 11 Merauke merupakan salah satu dari tiga sekolah negeri di Kecamatan Sota. Peserta didik SMPN 11 Merauke terdiri dari warga asli Papua, warga pendatang dari luar Papua, serta warga dari negara tetangga, Papua New Guinea (PNG). Peserta didik SMPN 11 Merauke pada tahun ajaran 2017/2018 berdasarkan data sekolah dari Kemendikbud (April, 2018) berjumlah 121 orang yang terdiri atas 62 lakilaki dan 59 perempuan. Jumlah rombongan kelas di sekolah ini adalah 5 yang diselenggarakan pada pagi hari.

Salah satu masalah yang ditemukan pada peserta didik SMP Negeri 11 Merauke adalah rendahnya hasil belajar peserta didik. Hal ini dapat dilihat dari hasil ujian nasional 3 tahun terakhir yang semakin menurun yang dapat dilihat pada tabel 1 .

\section{Tabel 1. Daftar Hasil Ujian Nasional 3 Tahun Terakhir

\begin{tabular}{llll}
\hline Tahun & 2015 & 2016 & 2017 \\
\hline
\end{tabular}

Nilai $\quad 70,40 \quad 68,82 \quad 35,88$

Sumber: http:pupendik.kemendikbud.go.id

(Kemdikbud, 2018)

Berdasarkan tabel 1, terlihat penurunan hasil ujian dari tahun 2015 ke tahun 2016 sebesar $2,2 \%$. Sementara itu, hasil ujian dari tahun 2016 ke tahun 2017 mengalami penurunan yang sangat tajam, yaitu mencapai $47,9 \%$. Salah satu faktor yang mempengaruhi penurunan nilai tersebut adalah ketidakmampuan guru untuk menyajikan pembelajaran dengan menggunakan media yang tepat kepada peserta didik sesuai dengan zamannya, misalnya dengan menggunakan media pembelajaran yang berbasis komputer. Salah satu media pembelajaran yang dianggap sangat cocok dengan karakteristik siswa dan lingkungan adalah PowerPoint.

Media pembelajaran merupakan alat bantu yang berfungsi untuk menjelaskan sebagian dari keseluruhan program pembelajaran yang sulit dijelaskan secara verbal (Abidin, Purnama, \& Nugroho, 2013). (Bahri, Arafah, \& Arsyad, 2017) menyatakan bahwa salah satu manfaat media PowerPoint pada pembelajaran fisika adalah menjadikan pembelajaran tersebut lebih konkret sehingga mudah dipahami oleh peserta didik. Selain itu, media pembelajaran juga dapat meningkatkan hasil belajar peserta didik (Fitryanti \& Siti Fatimah, 2014).

Salah satu media pembelajaran yang dapat digunakan untuk meningkatkan hasil belajar
IPA adalah PowerPoint. Penggunaan PowerPoint dapat meningkatkan pemahaman peserta didik terhadap penjelasan guru tentang suatu materi dan dapat mengetahui contoh materi belajar secara konkret sehingga peserta didik termotivasi untuk belajar dan mendapatkan hasil belajar yang maksimal (Tirtiana, 2013).

Akan tetapi, pembelajaran dengan visualisasi saja belum cukup jika diajarkan pada peserta didik yang berada di pedalaman atau pinggiran kota. Hal ini kerena mereka belum terbiasa melihat atau mengalami hal yang divisualkan. Misalnya, memperlihatkan proses pemuaian pada rel kereta api. Jika konsep ini divisualisasikan, akan menjadi sulit dimengerti peserta didik karena mereka belum pernah menemukan di Papua, khususnya Merauke.

Oleh karena itu, diperlukan pembelajaran yang bersifat kontekstual. Pembelajaran kontekstual sebagai suatu model pembelajaran yang memberikan fasilitas kepada siswa untuk belajar aktif melalui pengalaman konkret yang berhubungan dengan kehidupan nyata (Rusman, 2010).

Contoh integrasi pembelajaran kontekstual ke dalam PowerPoint: ketika peserta didik belajar tentang kapilaritas, adhesi, atau kohesi, maka guru dapat menggunakan media gambar 
atau video yang terkait dengan apa yang sering dialami, dilakukan, atau dilihat oleh peserta didik dalam kehidupan sehari-harinya. Misalnya, guru mengambil foto tembok rumah batu yang berada di pinggir rawa dan rumah batu yang jauh dari rawa. Pada foto atau video itu, guru bisa memperlihatkan contoh sekaligus menjelaskan konsep tentang kapilaritas. Contoh lain untuk menjelaskan konsep ini adalah sumbu kompor yang setiap hari dilihat oleh peserta didik.

Dengan demikian, pembelajaran kontekstual dengan menggunakan PowerPoint diharapkan dapat meningkatkan motivasi serta hasil belajar peserta didik. Selain itu, pembelajaran ini sangat penting karena merupakan implementasi dari pembelajaran dengan menggunakan scientific method (metode ilmiah), yaitu metode pembelajaran yang wajib digunakan di sekolah.

SMP Negeri 11 Merauke Distrik Sota dijadikan sebagai lokasi pengabdian karena sekolah ini berada di perbatasan sehingga memiliki peserta didik yang majemuk, bahkan berasal dari negera tetangga (PNG). Tujuan kegiatan ini adalah untuk meningkatkan kemampuan guru dalam mengembangkan media pembelajaran.

\section{METODE}

Kegiatan Pengabdian pada masyarakat ini dilaksanakan di SMP Negeri 11 Merauke Distrik Sota Kabupaten Merauke (Daerah Perbatasan RI-PNG) dengan jumlah subjek 15 orang guru. Guru di sekolah tersebut memiliki karakteristik yang hampir sama jika ditinjau dari kemampuannya dalam menggunakan komputer dengan tingkat kemampuan rata-rata mencapai $82 \%$ dari 20 indikator yang digunakan dalam pengukuran. Sementara itu, kemampuan dalam menggunakan PPT sebelum dilakukan pelatihan hanya mencapai $24,5 \%$. Adapun waktu pelaksanaan selama 2 bulanyaitu dari November 2018 -Desember 2018. Rangkaian kegiatan pengabdian ini terdiri atas workshop, pendampingan, dan evaluasi produk kegiatan.

\section{Workshop}

Pada kegiatan ini, dilakukan workshop

berupa pelatihan pembuatan media pembelajaran yang pada guru SMP Negeri
11 Merauke. Jumlah peserta workshop adalah 15 orang yang terdiri atas guru, pemateri, dan mahasiswa. Pelaksanaan workshop direncanakan di Aula SMP Negeri 11 Merauke atau ruangan kelas yang besar dengan tujuan agar dapat diperoleh pemetaan materi yang memerlukan media pembelajaran kontekstual dengan menggunakan PowerPoint. Hasil pemetaan materi ini menjadi dasar untuk mendesain/merancang media pembelajaran sesuai kebutuhan peserta didik sehingga penggunaannya lebih efektif, praktis dan efisien.

2. Pendampingan

Pendampingan dilakukan agar guru dapat mengetahui teknis pembuatan media pembelajaran baik dari aspek teori maupun praktik penggunaannya. Pada tahap ini, guru harus menghasilka media pembelajaran IPA yang siap digunakan.

3. Evaluasi produk kegiatan

Evaluasi produk yang dihasilkan dari kegiatan pengabdian berupa pengkajian tentang keefektifan, kepraktisan, dan kevalidan media pembelajaran yang dihasilkan. Evaluasi produk ini dilakukan dengan menggunakan kuesioner yang dibagikan kepada peserta didik SMP Negeri 11 Merauke tentang penggunaan media pembelajaran yang dihasilkan. Hasil evaluasi produk ini akan disampaikan kepada guru-guru untuk melakukan revisi terhadap tanggapan dan saran peserta didik. Selain itu, guru juga harus memperhatikan catatan yang diberikan oleh tim sebagai bahan revisi.

\section{HASIL DAN PEMBAHASAN}

Pelaksanaan kegiatan workshop pada guru-guru telah memberikan dampak pada peningkatan kemampuan guru di dalam menggunakan PPT. Peningkatan ini dapat dilihat dari adanya peningkatan persentase sebelum dan sesudah dilaksanakan kegiatan. Tingkat pengatahuan dan penguasaan peserta workshop sebelum diberikan workshop dapat dilihat pada gambar 1 .

Gambar 1. memperlihatkan bahwa pengetahuan dan penguasaan peserta tentang PowerPoint sangat rendah yaitu hanya mencapai $27,3 \%$. Ada beberapa indikator yang berada pada tingkat terendah di antaranya 
penggunaan toolbar; pengaturan slide, pemberian efek gerak dan efek suara, cara memasukkan gambar dan video, serta cara membuat hyperlink.

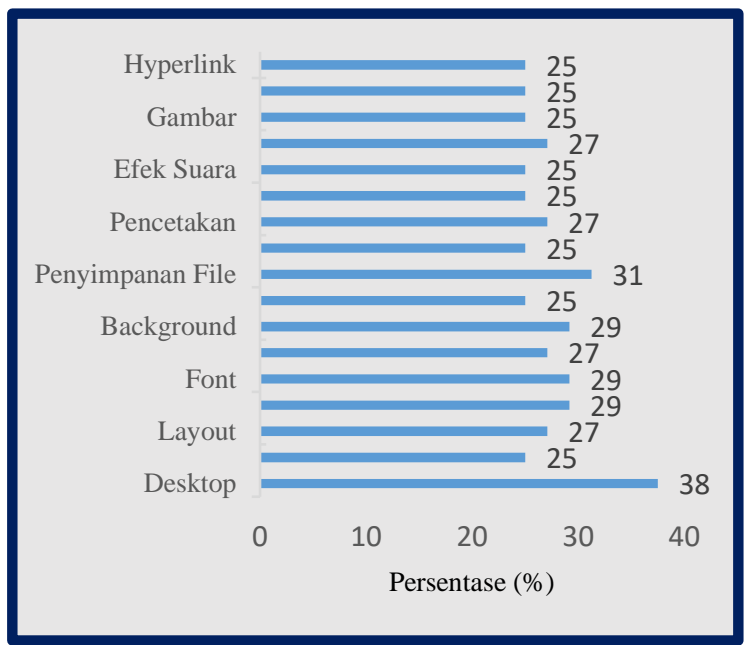

Gambar 1. Tingkat pengetahuan dan

penguasaan peserta workshop sebelum kegiatan

Pengetahuan dan penguasaan yang dimiliki oleh peserta menjadi dasar dalam menyusun materi workshop. Adapun hasil kegiatan pelaksanaan workshop berdasarkan indikator kemampuan menggunakan PowerPoint dapat dilihat pada gambar 2 .

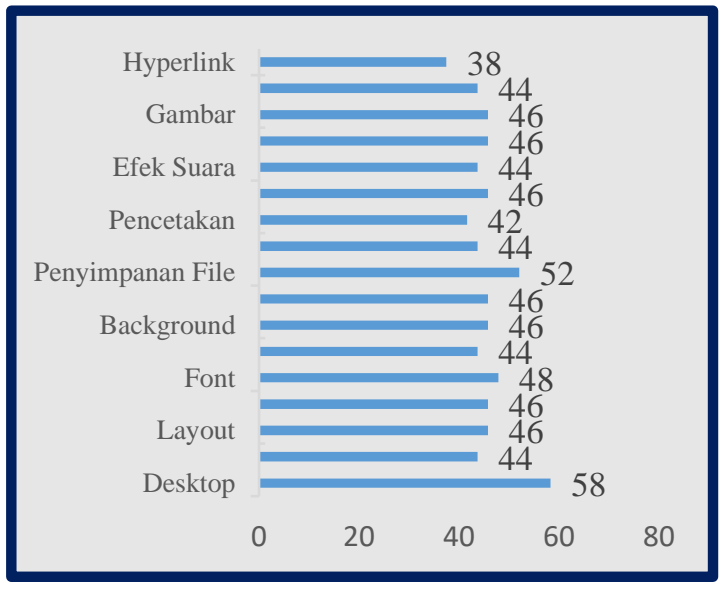

Gambar 2. Tingkat pengetahuan dan penguasaan peserta workshop setelah kegiatan

Secara umum, kegiatan workshop telah memberikan dampak pada peserta workshop. Meskipun masih dapam kategori rendah, namun terdapat peningkatan persentase pengetahuan dan kemampuan peserta dalam menggunakan PPT.

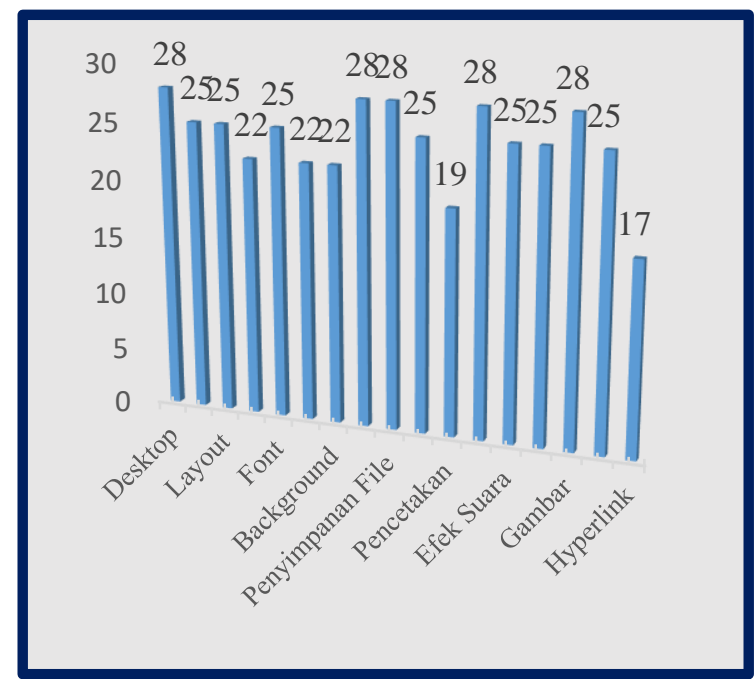

Gambar 3. Peningkatan pengetahuan dan penguasaan peserta workshop setelah kegiatan

Indikator kemampuan membuat hyperlink di dalam PPT menjadi hal yang paling sulit dilakukan oleh guru. Hal ini disebabkan oleh adanya beberapa istilah atau pilihan yang tidak dipahami pada saat hendak memasukkan hyperlink. Istilah atau pilihan yang dimaksud dapat dilihat pada gambar 4.

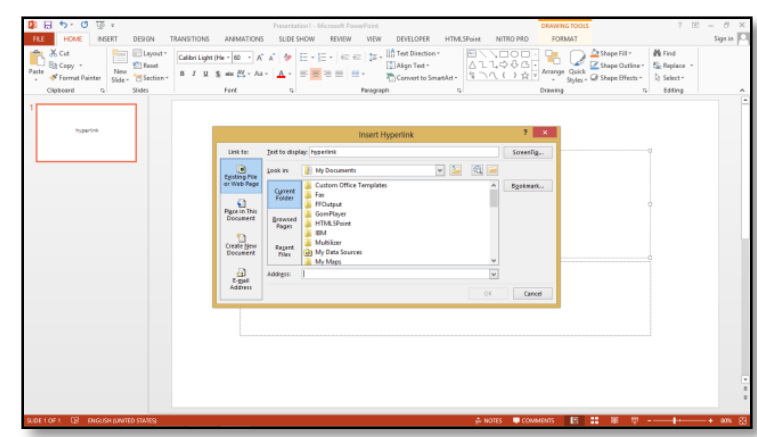

Gambar 4. Tampilan dialog box pada saat hendak memasukkan hyperlink

Solusi yang dapat ditempuh untuk masalah ini adalah dengan melakukan pelatihan yang lebih intensif serta pembiasaan menggunakan perangkat lunak ini. Hal ini sangat penting untuk dilakukan karena fitur PPT ini adalah salah satu fitur yang paling penting untuk membuat media pembelajaran berjalan dengan interaktif (Riasti, Suyatna, \& Ismu Wahyudi, 2016).

Sementara itu, ada beberapa indikator yang mengalami peningkatan paling besar jika dibandingkan dengan indikator-indikator lainnya. Pembuatan latar atau background 
merupakan salah satu aspek yang mengalami peningkatan setelah dilakukan pelatihan. Meskipun belum sempurna, namun para guru sudah mampu melakukan pergantian terhadap latar belakang slide PPT yang dibuat. Kesulitan yang dialami guru di dalam pembuatan background PPT adalah saat mengganti latar belakang slide pada slide tertentu. Saat guru mengganti background untuk slide tertentu, maka guru menerapkan background tersebut secara umum sehingga tidak ada perbedaan antara background slide tersebut dengan slide lain. Pembuatan latar belakang atau background mengalami peningkatan karena memang dalam pelaksanaan kegiatan, bagian ini dijelaskan lebih rinci, seperti cara membuat background yang khas atau menjadi penciri dari peserta. Penggunaan background berupa gambar ataupun warna yang tepat dan sesuai dengan tema pembelajaran membuat siswa tertarik di dalam proses pembelajaran (Ma'rifah \& Sumadi, 2016).

Penyimpanan file tentu bukanlah hal yang sulit untuk dilakukan. Namun, penyimpanan yang dimaksud oleh guru disini adalah penyimpanan yang dilakukan secara langsung dengan ekstensi PPT. Namun, jika guru diminta untuk menyimpan file PPT ke dalam ekstensi lain, guru belum mampu. Misalnya, guru diminta untuk menyimpan file dalam ekstensi .JPEG, maka guru sudah bingung dan tidak bisa melakukannya. Selain dalam ekstensi gambar, ada banyak penelitian yang mencoba untuk melakukan konversi dari PowerPoint menjadi video dengan ekstensi .mp4 sebagai salah satu media pembelajaran alternatif (Turrahmi, Yahya, \& Erfan, 2018). Hal ini tentunya perlu ditingkatkan pada pelatihan-pelatihan selanjutnya. Secara umum, faktor yang memudahkan penyimpanan file mengalami peningkatan karena memang peserta sudah memiliki pengetahuan awal mengenai cara menyimpan file MS Office, seperti microsft office word yang sudah familiar bagi mereka.

Pemberian efek gerak awalnya memang menjadi hal yang sulit untuk dilakukan oleh guru. Namun, setelah dilakukan pelatihan, guru menjadi lebih paham tentang bagaimana memberikan efek gerak, baik pada slide, pada teks, maupun pada gambar yang ditampilkan pada slide tersebut. Pemberian efek sangat mudah dilakukan karena toolbar efek gerak sudah lengkap pada menu bar yang disiapkan dalam PPT. Selain memberikan efek melalui toolbar, guru juga dapat memasukkan efek yang lebih praktis yang sudah berbentuk animasi. Penambahan animasi yang menarik ke dalam slide PPT akan membantu peserta didik untuk membangun konsep fisika (Khasanah \& Hidayati, 2017).

Gambar merupakan salah satu unsur penyusun yang paling penting dalam sebuah media pembelajaran fisika interaktif yang berbasis PPT (Riasti et al., 2016). Cara memasukkan gambar ke dalam slide juga merupakan hal yang sulit bagi guru sebelum dilakukan pelatihan. Setelah dilakukan pelatihan, maka guru mampu memasukkan gambar ke dalam slide, baik dengan melakukan cara copy-paste dari tempat penyimpanan file maupun melalui menu insert picture. Namun, jika dilihat lebih jauh, ternyata guru lebih suka memasukkann gambar ke dalam slide melalui cara copy-paste.

\section{SIMPULAN}

Hasil kegiatan workshop menunjukkan bahwa peserta mengalami peningkatan pengathuan dan kemampuan tentang PPT sebesar 24,5\%. Meskipun tekah mengalami peningkatan, namun pengetahuan dan kemampuan PPT peserta masih tergolong rendah.

Saran didasarkan pada hasil kegiatan ditujukan kepada seluruh stakeholder agar memfasilitasi peningkatan kemampuan TIK guru, khusunya yang berkaitan langsung dengan pembelajaran sehingga guru maupun lulusannya mampu bersaing dalam era revolusi industri 4.0.

\section{UCAPAN TERIMA KASIH}

Tim pengabdian pada masyarakat menyampaikan ucapan terima kasih kepada Bapak Rektor Universitas Musamus yang telah memberikan bantuan dana untuk pelaksanaan kegiatan pengabdian pada masyarakat melalui pembiyaan DIPA Unmus 2018. 


\section{DAFTAR PUSTAKA}

Abidin, M. M., Purnama, B. E., \& Nugroho, G. K. (2013). Pengembangan Media Pembelajaran Teknik Komputer Jaringan Kelas X Semester Ganjil pada Sekolah Mengengah Kejuruan Taruna Bangsa Pati Berbasis Multimedia Interaktif. IJNSIndonesian Journal on Networking and Security, 4(3).

Bahri, S., Arafah, K., \& Arsyad, M. (2017). Pengembangan Bahan Ajar Fisika Dasar I Berbasis Komputer. In M. Palobo, A. K. Hidayat, O. Dadi, \& Nataniel Reinold (Eds.), Seminar Nasional Pendidikan Inovasi Pendidikan dan Pembelajaran dalam Rangka Percepatan Pembangunan di Daerah Pinggiran (pp. 111-117). Merauke: FKIP Universitas Musamus.

Fitryanti, \& Siti Fatimah. (2014). Penggunaan Multimedia untuk Meningkatkan hasil Belajar Mahasiswa pada Mata Kuliah Akuntansi Perbankan di Program Studi Pendidikan Ekonomi. Jurnal Forum Sosial, 7(1), 3-15.

Kemdikbud. (2018). Data Pokok Pendidik Dasar dan Menengah Kementerian Pendidikan dan Kebudayaan. Retrieved April 12, 2018, from dapo.dikdasmen.kemdikbud.go.od/sekola h/ A3D9B8FDE3D04F4BAC44

Khasanah, N., \& Hidayati, Y. (2017). Pengaruh Pengguunaan LKS Berbantuan Media PowerPoint yang Dilengkapi Animasi pada Model Direct Instruction terhadap Pencapaian Kompetensi Fisika Siswa
Kelas X SMAN 5 Bukit tinggi. Pillar of Physics Education, 10(1), 65-72.

Ma'rifah, M., \& Sumadi. (2016). Pengaruh Penerapan Media PowerPoint dalam Pembelajaran Fisika terhadap Prestasi Belajar Fisika Pokok Bahasa Listrik Dinamis. Jurnal Ilmiah Pendidikan Fisika, 3(1), 96-103.

Riasti, M. F., Suyatna, A., \& Ismu Wahyudi. (2016). Pengembangan Media Interaktif Model Tutorial pada Materi Impuls dan Momentum. Jurnal Pembelaja, 4(1), 8191.

https://doi.org/10.1017/CBO9781107415 324.004

Rusman. (2010). Model-model Pembelajaran Mengembangkan Profesionalisme Guru. Jakarta: Raja Grafindo Persada.

Tirtiana, C. P. (2013). Pengaruh kreativitas belajar, penggunaan media pembelajaran powerpoint, dan lingkungan keluarga terhadap hasil belajar mata pelajaran akuntansi pada siswa kelas X AKT SMK Negeri 2 Blora Tahun Ajaran 2012/2013 (Motivasi belajar sebagai variabel intervening. Economic Education Analysis Journal, 2(2).

Turrahmi, N., Yahya, F., \& Erfan, M. (2018). Pengembangan Media Pembelajaran Video Berbasis Microsoft Office Power Point pada Materi Objek IPA dan Pengamatannya untuk SMP Kelas VII. QUARK: Jurnal Inovasi Pembelajaran Fisika Dan Teknologi, 1(1), 1-10. 